\title{
Low-Cost High Energy Density Material for Solar Thermal Heat Storage
}

\author{
Omar AL-Zoubi ${ }^{1)}$, Rebhi Damseh ${ }^{2)}$, Ghadeer Alblasmeh ${ }^{3)}$ \\ 1) Al al-Bayt University, Faculty of Engineering, Renewable Energy Engineering Department, P. O. BOX 130040, Mafraq, 25113 Jordan, \\ 2) Al-Balqa Applied University, Al-Huson University College, Mechanical Engineering Department, P.O.B 50, Irbid, 21510 Jordan \\ 3) \\ Al al-Bayt University, Prince Hussein Bin Abdullah College for Information Technology, Information Technology Department, P. O. BOX \\ 130040, Mafraq, 25113 Jordan
}

\begin{abstract}
A low-cost and enhanced thermal properties composite material for sensible heat storage in solar thermal energy storage applications is introduced. The proposed material is produced primarily for small scale solar thermal applications. However, it can be utilized for large scale solar thermal plants. The material has the advantages of high thermal conductivity and large energy storage density. The introduced material is composed of a mixture of cement and cast-iron particles. To obtain an optimal mixture, different samples of the material are prepared with different ratios of the cement-iron weights. The thermal conductivity of the produced samples is measured by using the linear heat conduction method. The specific heat capacity of the produced mixtures is calculated by using the Rule of the mixture. The obtained results show that the introduced material has a significant enhancement in thermal conductivity. Where, thermal conductivity as high as $\sim 6.0 \mathrm{~W} / \mathrm{m} . \mathrm{K}$ and energy storage density as high as $\sim 788 \mathrm{Joule} / \mathrm{cm}^{3}$ are achieved. The estimated volume energy density is $\sim 89 \%$ higher than that of water. The produced material has the advantage of high energy volume density, being unhazardous, chemically stable, eco-friendly, easy to fabricate, and integrate with solar thermal energy systems and is a low-cost material.
\end{abstract}

Keywords: Sensible heat storage; Solar thermal energy; Cement-iron mixture materials; Cementous based materials; Energy volume density.

\section{Introduction}

Solar energy is one of the major sources of renewable energy, and solar thermal energy is considered one of the important forms of solar energy. In general, energy storage is considered a key element and a major challenge in the solar energy industry. In solar thermal energy plants, thermal energy storage (TES) is considered a key element for improving solar thermal power plants and their dispatchability, (Sarada et al, 2013, Breeze 2019, Matthias et al, 2011). Different approaches have been proposed in the literature to store thermal energy by using different types of materials, liquids, solids, and, phase change materials (Alva et al., 2017, Alva et al, 2018, Ndiaye et al., 2018, Ioan and Calin, 2018). Nevertheless, thermal energy storage methods can be categorized into three main categories: Sensible Heat Storage (SHS), Latent Heat Storage (LHS), and thermochemical storage ( Ioan and Calin, 2018). The most direct and lowest cost method to store thermal energy is the sensible heat storage (SHS), which utilize solid, liquid, or gaseous material for heat storage. Different solid materials can be utilized to achieve SHS such as sand rock minerals, reinforced concrete, and cast steel. The excellent work of ( Ioan and Calin, 2018) presents the most popular materials and techniques that are utilized for TES in general and SHS. The method of SHS is based on raising the temperature of a liquid or solid material to store heat by raising their temperature and retrieving it when it is required by decreasing their temperature. Despite that the method of SHS is considered less efficient for heat storage, it is inexpensive and less complicated in comparison with latent or chemical heat storage methods. For these reasons, the SHS is highly recommended for small scale solar thermal systems. The materials that are utilized for SHS are highly desired to have a high specific heat capacity_and thermal conductivity. Besides, the materials utilized in SHS are required to be chemically stable, unhazardous, inflammable, and can withstand high temperatures. Concrete is a highly promising material for SHS, which has some of the desired properties in SHS as reported by many authors (Laing et al., 2008, Ndiaye et al., 2018, Laing and Zunft, 2015, Majdi et al., 2010). Concrete has good thermal specific heat capacity, good conductivity, and can withstand high temperatures (Miah et al., 2020, Ndiaye et al., 2018). Moreover, it is chemically stable, inflammable, and safe to use. However, a high specific heat capacity with low thermal conductivity renders an SHS material useless during thermal energy charging and discharging cycles. Therefore, enhancing the thermal conductivity of an SHS material is highly important for achieving very good dispatchability in solar thermal systems.

Received on June 21, 2020; accepted on August 6, 2020, Correspondence concerning this article should be addressed to Rebhi Damseh (E-email address: rdamseh@bau.edu.jo)._ORCiD ID for Rebhi Damseh https://orcid.org/0000-0001-5127-750X. 
The amount of energy stored in an SHS material depends on the specific heat capacity of the medium, the temperature change, and the amount of the used material. To obtain optimal performance and the low-cost and simple storage system for small scale solar thermal systems, we use pure cement and waste cast-iron particles in the form of a mixture as an SHS material. Worth mentioning that this mixture is different than typical concrete, which is usually composed of different parts of cement, silica sand, and other aggregate materials. Based on that, the motivation of this work is to produce a simple, low-cost, enhanced thermal properties, large energy storage density, and high thermal conductivity SHS material for solar thermal heat storage applications.

\section{Materials and Methods}

The material introduced in this work is a solid SHS material and intended to be produced from low cost and commercially available materials. Moreover, this material is intended to be easy to fabricate, inflammable, safe to use, eco-friendly, and safe to dispose of. For these reasons and being promising material for SHS, the widely used material in constructions, Portland cement, is selected. The waste cast iron particles from workshops are utilized as an additive to the pure cement to enhance its thermal properties, especially thermal conductivity. Portland cement produced by Lafarge factory/Jordan is utilized in this work. The Portland cement is composed of Calcium oxide $(\mathrm{CaO}, 64.6 \%)$, Silicon dioxide $\left(\mathrm{SiO}_{2}, 21.3 \%\right)$, Aluminum oxide $\left(\mathrm{Al}_{2} \mathrm{O}_{3}, 5.6 \%\right)$, Ferric oxide $\left(\mathrm{Fe}_{2} \mathrm{O}_{3}, 3.3 \%\right)$, Sulfur trioxide $\left(\mathrm{SO}_{3}, 2.1 \%\right)$, other additives $(3.1 \%)$. The included material into the cement is cast iron particle waste collected from workshops. These iron particles are obtained from the remains and waste of industrial processes that use cast iron for the manufacturing of different furniture items. The mass density of the cast iron bulk is $\sim 7.34$ $\mathrm{gm} / \mathrm{cm}^{3}$, and the pure cement mortar density is $\sim 1.95 \mathrm{gm} / \mathrm{cm}^{3}$. Whereas the average density of the cast iron particles is $\sim 5.00$ $\mathrm{gm} / \mathrm{cm}^{3}$. The thermal conductivity of pure cement mortar and the bulk of cast iron is $\sim 1.9 \mathrm{~W} / \mathrm{m} . \mathrm{K}$ and $\sim 25.0 \mathrm{~W} / \mathrm{m} . \mathrm{K}$, successively. The thermal conductivity of these materials is measured by using the HT11C linear heat conduction device at ambient temperature, where three samples of the cast iron bulk and the pure cement mortar are used to conduct measurements, as described in Section "Thermal Conductivity Measurements" of this work. Mass density measurements are conducted by the simple technique of measuring weight and divide by the measured volume of the samples. The average value of the thermal conductivity and mass density of the cast iron and the pure cement mortar are close to those values reported in the literature (Helsing and Grimvall, 1991). Cast iron particles size analysis: The collected sample of cast iron particles, used in this particular work, have a broad range of sizes and shapes. The distribution of the length of the particles extends between $\sim 50$ and $\sim 1000 \mu \mathrm{m}$. The distribution of the particle size, analyzed by particle size analyzer software ( MIPAR software, 2020), is shown in Figure 1. Worth to mention that the particle size, shape, and their statistical distribution plays a role in the thermal properties of the mixtures. Further statistical analysis of the particle size distribution shows that the particle size (in terms of maximum particle length) has approximately a Gaussian distribution with a mean value of $\sim 435$ $\mu \mathrm{m}$ and a standard deviation of $\sim$ 140. Figure 2 shows SEM images of a cross-section of the material loaded with waste iron particles that take different sizes and shapes. The thermal properties of materials, thermal conductivity, and specific heat capacity can be calculated theoretically by different methods. These thermal properties can also be experimentally measured by different methods. For example, thermal conductivity can be measured by using different techniques such as Fourier linear

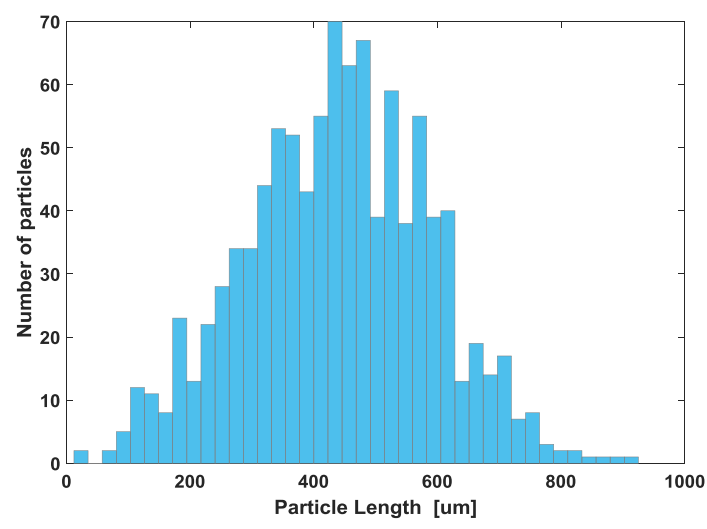

Fig. 1 The histogram of the cast iron particle size, in terms of maximum length of the particles. conduction method. In this work, the experimental approach is adopted to measure the thermal conductivity of the proposed SHS mixture. The specific heat capacity of the produced material 
samples is calculated theoretically by using the Rule of mixtures, which gives reasonable accuracy of the values of the specific heat capacity. In the following subsections, we briefly describe both techniques: the theoretical basis for the calculation of the specific heat capacity and the experimental method and tools for measuring the thermal conductivity.
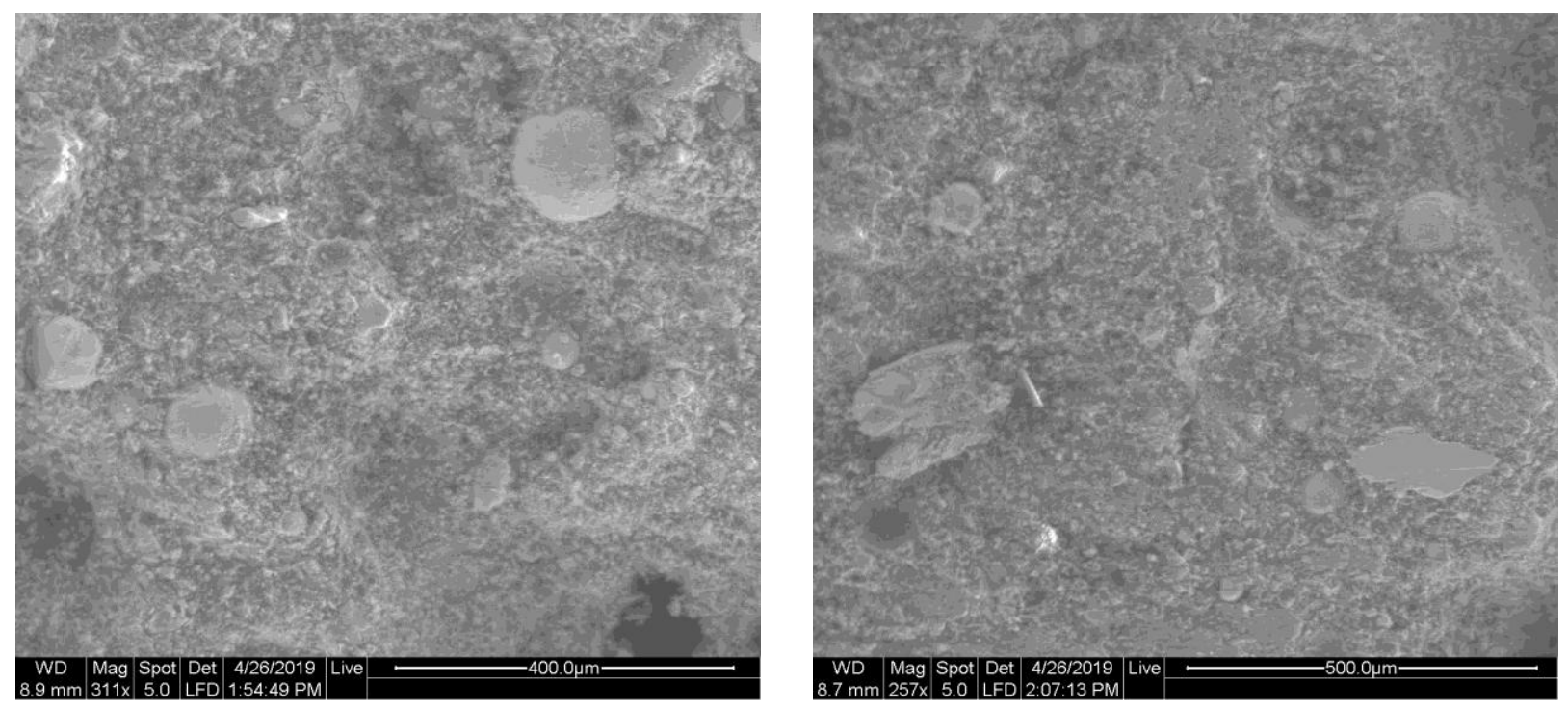

Fig. 2 Images of different sizes and shapes iron particles under a scanning electron microscope (SEM): (left) scale of $400 \mu \mathrm{m}$, and (right) scale of $500 \mu \mathrm{m}$.

\subsection{Specific heat capacity}

The cement-iron mixture can take many forms. For example, iron powder particles loaded into the cement to form a mixture as shown in Figure 3(a). Another example is to have iron fibers randomly loaded into the cement, or long iron fibers regularly inserted in the mixture with continuous heat conduction, as shown in Fig. 3(c). Each form of these cement-iron mixtures can have different thermal properties, especially thermal conductivity.

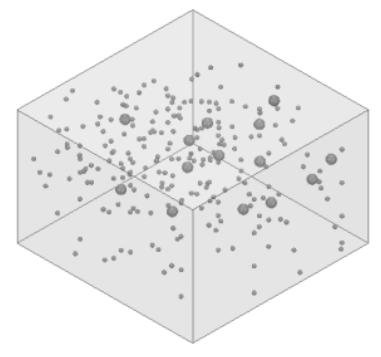

(a) Iron particles

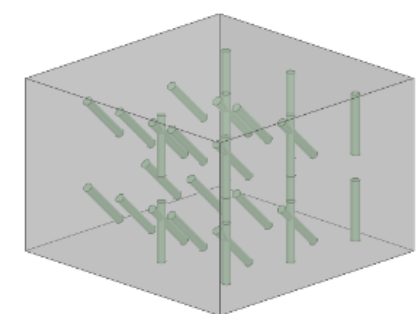

(b) Short iron fibers whisker

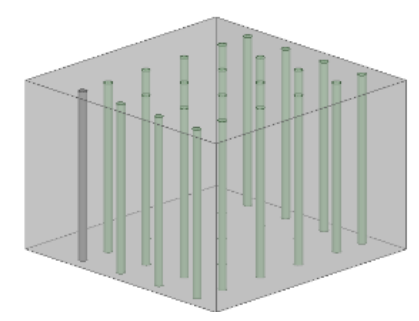

(c) Continous iron fibers

Fig. 3 Different configurations of concrete-metal composite: (a) Cement with random size iron powder particles (b) Cement with iron fibers whisker (c) Cement with continuous iron fibers.

Generally, the specific heat capacity can be calculated for composite materials by the rule of the mixture:

$$
C_{\text {pcomposite }}=\sum M_{i} C_{p i}
$$

where $\mathrm{C}_{p c o m p o s i t e}$ is the composite's specific heat capacity, and $M_{i}$ and $C_{p i}$ are the component's mass fraction and specific heat 
capacity, respectively. In this current work, it is utilized the Rule of mixtures to calculate the SHC of the proposed composite material. For the mixtures composed of two materials, cement, and iron powder in this work, the SHC can be calculated by the expansion of Equation 1 as:

$$
C_{p, \text { composite }}=\left(\frac{m_{1}}{m_{\text {composite }}}\right) C_{p 1}+\left(\frac{m_{2}}{m_{\text {composite }}}\right) C_{p 2}
$$

where $m_{1}$ is the mass of the cement material in the composite, $m_{2}$ is the mass of the iron particle material included in the composite, $m_{\text {composite }}$ is the mass of material's composite, $C_{p 1}$ is the specific heat capacity of the cement, $C_{p 2} i s$ the specific heat capacity of the intruded material (iron particles).

\subsection{Thermal conductivity measurements}

Effective thermal conductivity of composite material can be calculated theoretically by using different mathematical models (Pietrak and Wiśniewski, 2015), such as (Maxwell, 1904 and Davis, 1986). Nevertheless, The most general formula for calculating the thermal conductivity of mixtures is the Rule of mixtures, which can be written as (Zare and Kargari, 2018):

$$
k_{c}=f k_{f}+(1-f) k_{m}
$$

where $k_{c}$ is the mixture thermal conductivity, $f$ is the volume ratio of included material, $k_{f}$ is the thermal conductivity of the included material, and $k_{m}$ is the thermal conductivity of the hosting material. In this work, the experimental approach to measure the thermal conductivity is conducted by using the linear heat conduction method. To measure the thermal conductivity of solid materials, a common method is to insert it between two copper blocks with an identical cross-sectional area. A heat source and heat sink are attached to the copper blocks. The heat source passes heat flow to the material under the test and the copper blocks. Figure 4 illustrates a common setup for thermal conductivity measurements. Eight thermocouples are connected to the locations as indicated in Figure 4 to measure the local temperature. The device, HT11, and accessories from Armfield company products are utilized to conduct the measurements on the samples. To ensure the accuracy of the measurements, the device calibrated by measuring a reference sample of brass with well-known thermal conductivity. When conducting the measurements, the sample under test is inserted between a heat source and a heat sink as shown in Fig. 4. The well thermally insulated sample is heated by a heat source with known steady-state power input. The resulting temperature drop $\Delta T$ across the sample is measured by temperature sensors (thermocouples) after a steady-state temperature distribution is achieved. Thermal conductivity $k$ of the sample can be calculated using Fourier's law of heat conduction (Zhao et al., 2016):

$$
k=\frac{Q L}{A \Delta T}
$$

where $Q$ is the amount of heat that flows through the sample, $A$ is the area of the cross-sectional of the sample, $L$ and $\Delta T$ are the distance and temperature difference between temperature sensors(Zhao et al., 2016).

\subsection{Samples preparation}

Different samples are prepared with different weight fractions of iron powder in the mixture. Each lot of the cement-iron mixture is divided into three identical samples, as Table 1.

Three samples are prepared from the same mixture lot. Later, measurements are conducted on each of these three samples from the same mixture lot. The thermal conductivity is considered as the average value obtained from the three samples. The samples are prepared by following a procedure that ensures a homogeneous distribution of the iron particles in the cement paste. To this target, the first step is to conduct dry mixing of Portland cement powder with the cast iron waste. Later, water is added gradually to the dry mixture with a continuous mixing by using a handheld mixing machine with a rotation speed of 100 revolutions per minute. To reach a satisfactory level of homogeneity, a fairly long time of dry and wet mixing is followed. The weight of the added water to the mixture is approximately $50 \%$ of the total weight of the dry mixture. Then, the prepared wet mixture, in the

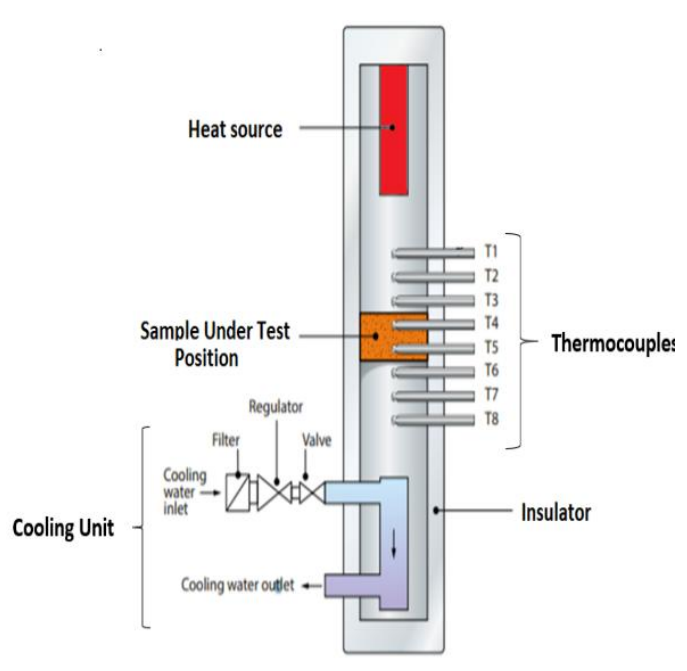

Fig. 4 Schematic of the device that implements the linear heat conduction method for measuring thermal conductivity 
form of a paste, is poured into a circular cylinder shape mold with a $2.5 \mathrm{~cm}$ diameter and a $3 \mathrm{~cm}$ height.

Finally, the produced samples are cured for 28 days in a hot dry environment. Figure 5 shows a depiction and dimensions of the produced samples, where Fig. 5(a) shows a sample produced from pure cement and Fig. 5(b) shows the cement-iron powder samples.

Figure 6 shows the iron powder and some of the produced samples. These samples are carefully produced to have the same cross-section and area of the copper cylinders in the measurement device. The height of the produced circular cylinder is precisely adjusted to be $30 \mathrm{~mm}$. A very thin layer of a conductive thermal paste is added to the top and bottom of the samples to ensure firm thermal contact between the samples and the copper heat sink and source.

Table 1: Produced samples and their eight ratios

\begin{tabular}{ccc}
\hline Sample No. & $\begin{array}{c}\text { Iron particle weight } \\
\text { percentage }(\%)\end{array}$ & $\begin{array}{c}\text { Iron particle volume } \\
\text { percentage }(\%)\end{array}$ \\
\hline $1-3$ & 0 & 0 \\
$4-6$ & 20 & $\sim 9.0$ \\
$7-9$ & 33 & $\sim 16.6$ \\
$10-12$ & 43 & $\sim 23.1$ \\
$13-15$ & 50 & $\sim 28.6$ \\
$16-18$ & 55 & $\sim 33.3$ \\
\hline
\end{tabular}

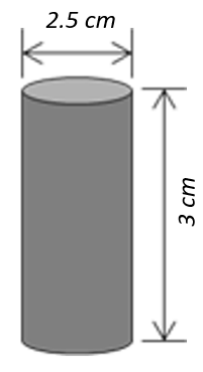

(a)

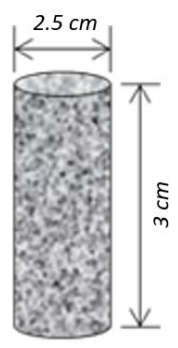

(b)
Fig. 5 (a) 3D depiction of the produced samples pure cement sample (b) mixture composed of cement and iron powder particles.

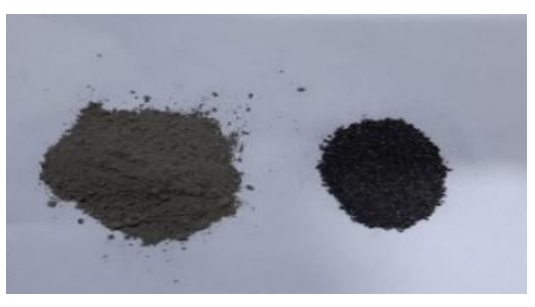

(a)

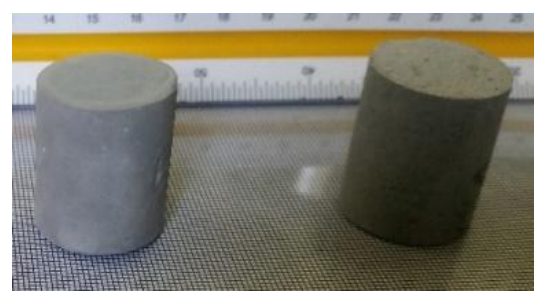

(b)

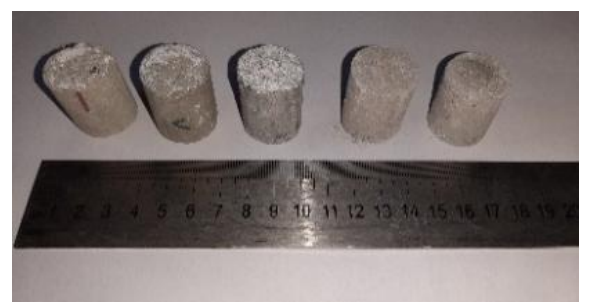

(c)

Left cement powder, right iron powder

Fig. 6 (a) Cement and iron powder particles used in this study, (b) Circular cylinders samples produced: pure cement to the left and cement-iron mixture to the right, (c) Different samples with different iron weight ratios.

\subsection{Experiment setup and measurements}

The produced samples are cured for 28 days and then inserted into the holding device that is part of the device utilized to measure the thermal conductivity. Armfield Company devices are implemented to measure the thermal conductivity, where Figure 7(a) shows the holing unit contains the brass sample that is used for device calibration. Fig. 7(b, and c) show the insertion of the sample under test inside the holding unit. The thermal properties of the material are measured by using the Linear Heat Conduction -HT11 device, supported by computer-controlled Linear Heat Conduction HT11C unit, and HT10XC ComputerControlled Heat Transfer Service Unit. Figure 8(a) shows the HT11C linear heat conduction device utilized for performing the thermal conductivity measurements and the position of the test sample. 


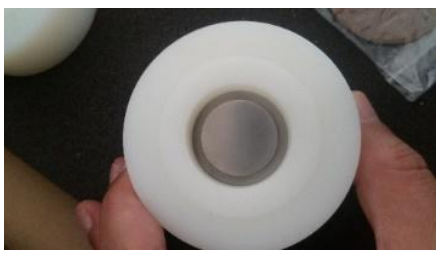

(a)

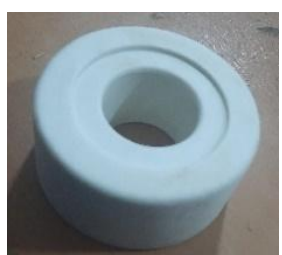

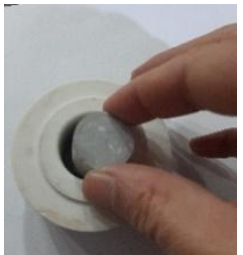

(b)

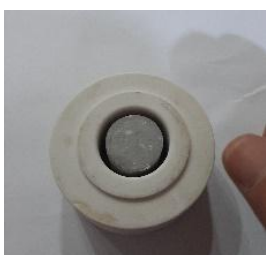

Fig. 7 Samples insertion in the holder that is attached in the measurement of thermal conductivity: (a) Shows the reference sample used for device calibration, (b) sample insertion into the measurement device.

Fig. 8(b) shows the heat transfer service unit, HT10XC, which controls the heating and cooling of the heat source and heat sink attached to the unit under test. Several thermocouples are attached to the measurement unit, where the HT10XC unit acquires the temperature readings and relays it to a PC for analyses. The sample holder, in the HT11C unit, is firmly attached between the heat sink and source. To ensure well heat conduction between the sample and the copper heat source and sink, a thermally conductive paste is applied to the surface of the sample. Figure 8(a) indicates the position of the sample under test in the device.

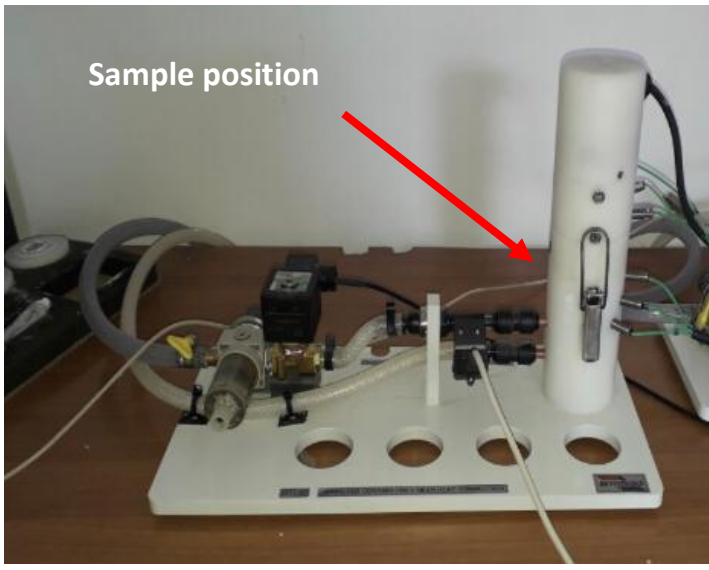

(a)

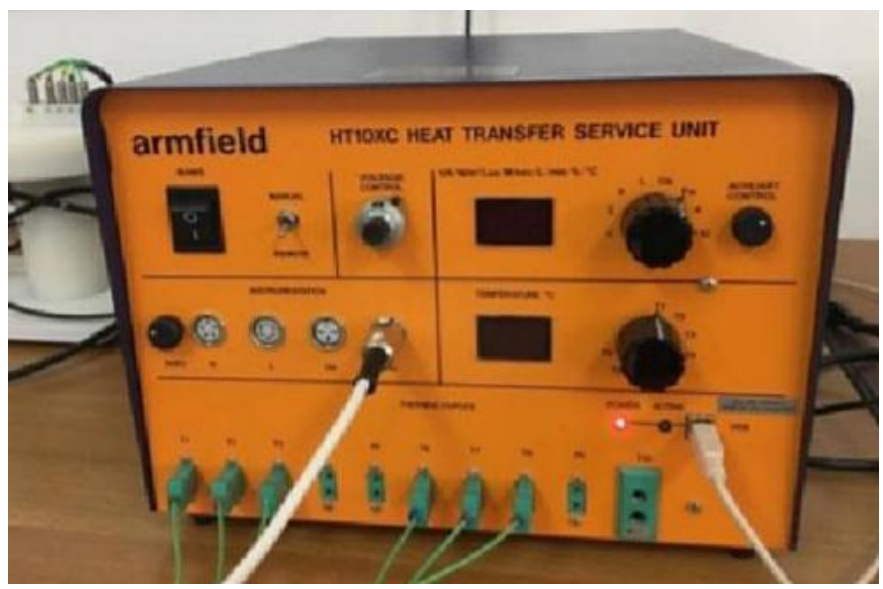

(b)

Fig. 8 (a) Armfield Linear Heat Conduction Accessory: Computer Controlled Linear Heat Conduction-HT11C unit, (b) Heat transfer service unit, HT10XC.

The controlled heat source and heat sink device are run until reaching a stable heat conduction state. The HT10XC controls the heat source and sink and acquires temperature measurements and transmits to a PC where the thermal conductivity is calculated. Further details about the measurement procedure and analysis steps can be found in Armfield HT11 technical manuals ( Armfield, 2020). The thermal conductivity measurements are performed according to the ASTM D5470 standard. Accuracy of the results is based on the heat losses and the accuracy of the temperature measurements that are based on thermocouples' accuracy (Zhao et al., 2016). The implemented thermocouples in this device are selected to have less than $1 \%$ temperature measurement error as in the device technical manual (Armfield, 2020). The samples are well thermally insulated to minimize the heat losses that can affect measurement accuracy. By following the experimental procedures in the HT11 technical manual, and using a well-known thermal conductivity sample, bronze, the obtained results show that the calibrated test rig accuracy is in the order of less than $5 \%$.

\section{Results and Discussion}

The measured thermal conductivity of the different sample shows significant enhancement results in terms of thermal conductivity and energy storage density. The produced samples have different iron weight ratios, different mass densities, and specific heat capacities. Table 2 shows the specific heat capacity, thermal conductivity, and mass density of the different produced samples. One can see that the thermal conductivity of the cement can be enhanced significantly by increasing the iron weight ratio.

\subsection{Energy Storage density}

Energy Density can be defined as the total amount of energy stored in a system per unit volume. In SHS materials, the stored heat 
energy in a certain mass is calculated as (Nomura et al., 2010):

$$
\Delta Q=m \cdot \int_{T 1}^{T 2} C_{p}(T) \cdot d T
$$

where $\Delta Q$ is the energy stored in Joule, $m$ is the mass of an object in $\mathrm{kg}, C_{p}(T)$ is the specific heat capacity as a function of temperature in $\mathrm{J} / \mathrm{g} . \mathrm{K}$, and $d T$ is the temperature difference. The amount of energy in sensible heat storage (SHS) medium depends on its mass density, specific heat capacity, and temperature difference that the medium can withstand. Therefore, the energy density depends on the material mass density and its specific heat capacity. Assuming the specific heat capacity of a material to be constant with temperature changes, the amount of stored energy can be written as:

$$
\Delta Q=m \cdot C_{p} \cdot \Delta T
$$

In small scale solar thermal energy systems, the limited available volume urges us to enhance the mass density to obtain as large energy storage as possible. Moreover, the SHS heat storage material must withstand high temperatures and a wide range of temperature variations. In a limited volume, as in small scale solar thermal systems, the mass density $\rho$ of the SHS material is a key factor for enhancing its energy storage density. As the mass density increases the energy density increases. For this reason, we have a target in this work to increase the density of the mixture mass density as much as possible. On one hand, increasing the density of the proposed material increases energy volume density. On the other hand, as the density increases the specific heat decreases as shown in Figure 10. These competing factors are studied to reach an optimal mass density and specific heat capacity for optimal energy storage density.

\subsection{Thermal conductivity}

Enhancing the thermal conductivity of the heat storage medium is a major target of this work. Another target is to enhance energy volume density. As equation 5 indicates, as mass density increases the energy storage density increases. Therefore, enhancing the density of the cement-iron mixture is required. However, increasing the density of the mixture by increasing the weight fraction of the iron powder decreases the specific heat capacity of the mixture. These contradicting factors require optimization of the mixture ratios to reach the optimal energy storage density and thermal conductivity. Table 2 shows the measured thermal conductivity, mass density, the specific heat capacity, and the calculated energy storage density of the different produced samples.

\begin{tabular}{|c|c|c|c|c|c|c|c|c|}
\hline \multirow[t]{2}{*}{$\begin{array}{c}\text { Sample } \\
\text { No. }\end{array}$} & \multirow[t]{2}{*}{$\begin{array}{l}\text { Weight } \\
\text { Ratio } \\
\text { (Iron) }\end{array}$} & \multicolumn{2}{|c|}{$\begin{array}{c}\text { Density } \\
\left(\mathrm{gm} / \mathrm{cm}^{3}\right)\end{array}$} & \multicolumn{2}{|c|}{$\begin{array}{c}\text { Measured } \\
\text { Thermal Conductivity } \\
(\mathrm{W} / \mathrm{m} \cdot \mathrm{K})\end{array}$} & \multirow{2}{*}{$\begin{array}{l}\text { Calculated } \\
\text { Thermal } \\
\text { Conductivity } \\
\text { (W/m.K) }\end{array}$} & \multirow{2}{*}{$\begin{array}{c}\text { Calculated } \\
\text { Specific heat } \\
\text { capacity, } \\
\text { (Average) } \\
\text { (Joule/g.K) }\end{array}$} & \multirow{2}{*}{$\begin{array}{c}\text { Average } \\
\text { Energy storage } \\
\text { density } \\
\left(\text { Joule } / \mathrm{cm}^{3}\right)\end{array}$} \\
\hline & & Measured & Average & Measured & Average & & & \\
\hline 18 & & $\sim 3.20$ & & $\sim 6.10$ & & & & \\
\hline 17 & $55 \%$ & $\sim 3.10$ & $\sim 3.14$ & $\sim 6.05$ & $\sim 6.07$ & $\sim 8.50$ & $\sim 0.67$ & $\sim 788$ \\
\hline 16 & & $\sim 3.12$ & & $\sim 6.06$ & & & & \\
\hline 15 & & $\sim 3.10$ & & $\sim 6.01$ & & & & \\
\hline 14 & $50 \%$ & $\sim 2.85$ & $\sim 2.95$ & $\sim 6.00$ & $\sim 6.00$ & $\sim 7.49$ & $\sim 0.70$ & $\sim 782$ \\
\hline 13 & & $\sim 2.91$ & & $\sim 5.90$ & & & & \\
\hline 12 & & $\sim 2.77$ & & $\sim 5.80$ & & & & \\
\hline 11 & $43 \%$ & $\sim 2.70$ & $\sim 2.91$ & $\sim 5.80$ & $\sim 5.78$ & $\sim 6.03$ & $\sim 0.75$ & $\sim 748$ \\
\hline 10 & & $\sim 2.66$ & & $\sim 5.75$ & & & & \\
\hline 9 & & $\sim 2.55$ & & $\sim 4.80$ & & & & \\
\hline 8 & $33 \%$ & $\sim 2.50$ & $\sim 2.50$ & $\sim 4.80$ & $\sim 4.80$ & $\sim 5.01$ & $\sim 0.79$ & $\sim 725$ \\
\hline 7 & & $\sim 2.44$ & & $\sim 4.79$ & & & & \\
\hline 6 & & $\sim 2.25$ & & $\sim 3.67$ & & & & \\
\hline 5 & $20 \%$ & $\sim 2.20$ & $\sim 2.18$ & $\sim 3.60$ & $\sim 3.61$ & $\sim 3.57$ & $\sim 0.83$ & $\sim 672$ \\
\hline 4 & & $\sim 2.10$ & & $\sim 3.55$ & & & & \\
\hline 3 & & $\sim 1.90$ & & $\sim 2.01$ & & & & \\
\hline 2 & 0 & $\sim 1.97$ & $\sim 1.95$ & $\sim 2.00$ & $\sim 1.97$ & $\sim 1.90$ & $\sim 0.92$ & $\sim 665$ \\
\hline 1 & & 1.98 & & $\sim 1.90$ & & & & \\
\hline
\end{tabular}

Table 2. The measured thermal conductivity, the calculated specific heat capacity, and the average volume energy density. Assuming $\Delta T=$

It can be seen that the thermal conductivity of the $55 \%$ iron weight ratio is enhanced by $\sim 3$ manifolds relative to the pure cement sample. While the specific heat capacity is degraded slightly but the mass density is enhanced by $\sim 3$ manifold of that of the pure 
cement. As Table 2 shows, the energy volume density of the $55 \%$ iron weight ratio is enhanced by $\sim 18 \%$ over that of the pure cement sample. The energy storage density trend is to increase as the iron powder weight ratio increases. This can be seen also in Figure 9, which shows the relation between the iron weight ratio and the energy storage density of the produced mixtures. One can see that the energy density increases as the iron weight ratio increases in the range of over $20 \%$. And as the weight ratio increases the energy density increases. Whereas, the specific heat capacity decreases slightly as the weight ratio increases. The slight decrease in the specific heat capacity of the mixture is expected since the included cast iron has much lower specific heat capacity relative to cement mortar (Chen et al., 2009). However, this degradation of the specific heat capacity is compensated by the increase in the overall mixture mass density, as can be seen in Figure 10. It can be seen that increasing the iron particles weight ratio in the mixture increases the density, thermal conductivity, and the energy storage density, but decreasing the specific heat capacity.

Fig. 10 shows the measured and calculated thermal conductivity, the calculated specific heat capacity, and the calculated energy storage density of the mixture versus the cast-iron particle weight ratio. It can be seen that the thermal conductivity of the mixture increases in a linear trend below the $40 \%$ range weight ratio. Whereas, it slightly increases, as the iron weight ratio increases in the range of over $40 \%$. The trend of the measured thermal conductivity vs the cast-iron weight ration is similar to the trend of the calculated thermal conductivity by using Eq.3 up to $40 \%$ weight ratio. Above the $40 \%$ weight ratio, it can be seen that the measured thermal conductivity would not increase significantly. Therefore, the $\sim 40 \%$ castiron weight ratio would be sufficient for enhancing thermal conductivity and can be considered the optimal mixture ratio. The no similarity in the measured and calculated values of the thermal conductivity above the $\sim 40 \%$ can be attributed to the

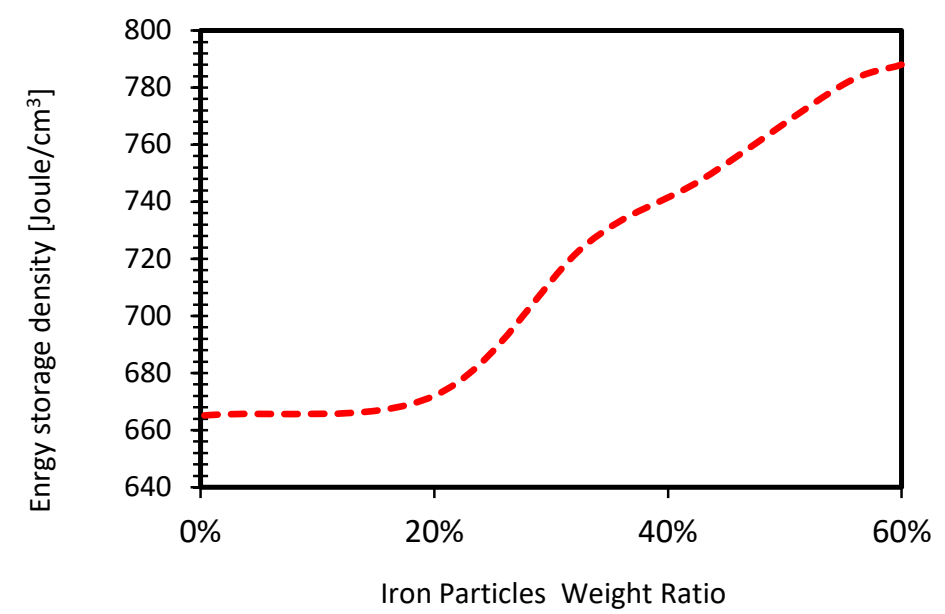

Fig. 9 The weight ratio of the iron particles in the material vs the energy storage density.

fact that calculations are based on Eq. 3 which is a general rule of mixtures. Equation 3 does not consider the added material, castiron particles, shape, size, and distribution of the included material. However, increasing the iron particle weight ratio leads to further enhancement of the mass density and, hence, enhancement of energy storage density. Further investigation of Figure 10 tells that the $\sim 50 \%$ iron particle weight ratio would yield a $\sim 3$ manifold enhancements on thermal conductivity, and $\sim 17 \%$ enhancement on the storage density over that of the pure cement. The thermal conductivity enhancement is the main scope of this work, which is a key element in producing good quality SHS materials. 


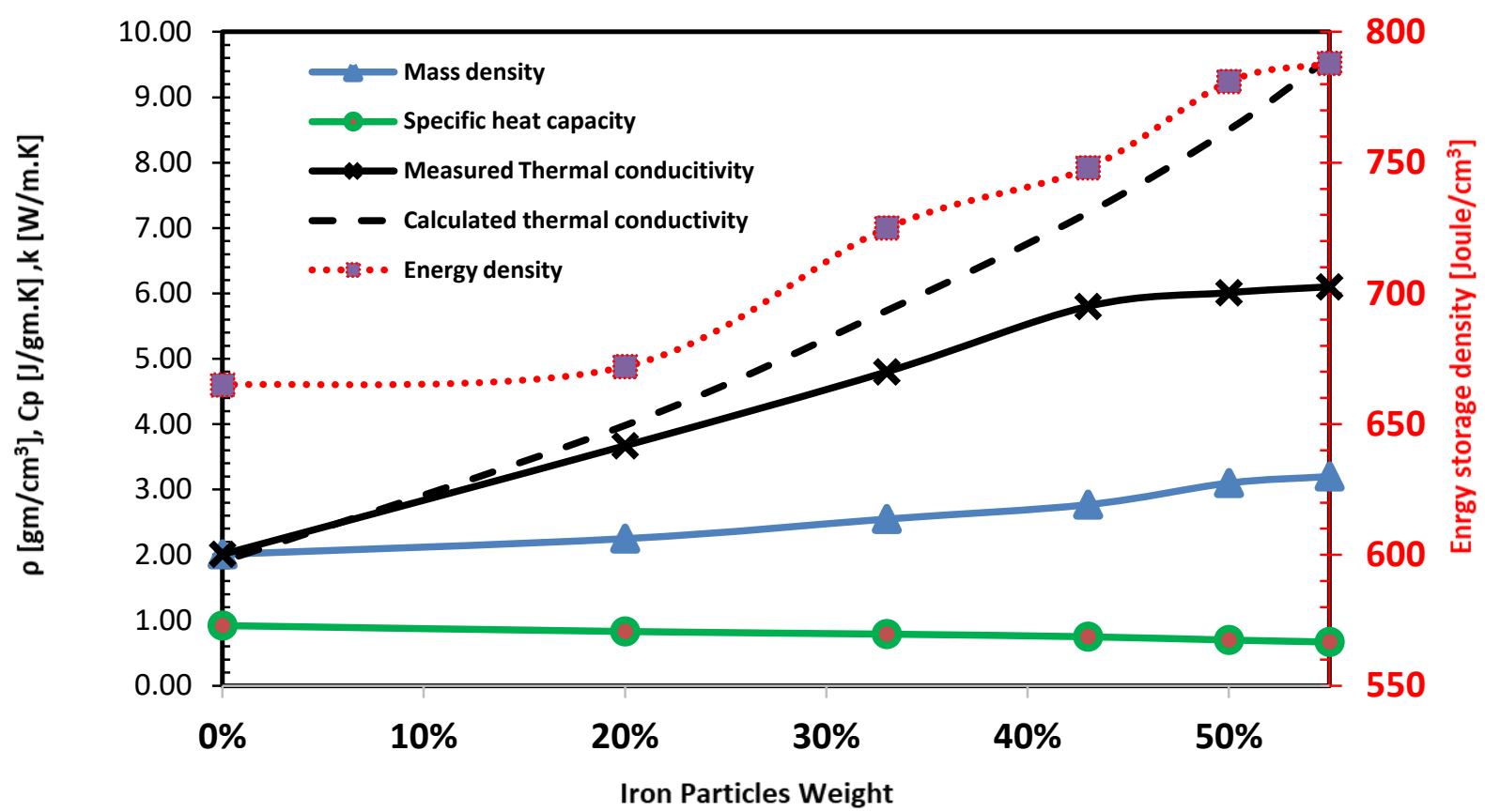

Fig. 10 The weight ratio of the iron particles in the mixture vs the energy storage density, mass density, specific heat capacity, and measured and calculated thermal conductivities.

As a demonstration example about the performance of the produced mixture, a volume of 10 liters size of the optimal mixture would store an amount of energy as $\sim 7.88 \mathrm{MJ}$, assuming $\Delta T$ to be $360^{\circ} \mathrm{C}$. In a typical heat storage system using water, such volume would store $\sim 4.18 \mathrm{Mega}$ joules, assuming the maximum tolerable $\Delta T$ to be $90^{\circ} \mathrm{C}$. This means that in similar volumes of the mixture and water, the mixture has $\sim 89 \%$ volume storage density enhancement over that of water. This is attributed to the fact that water withstands a limited range of temperature differences, whereas the mixture can withstand as high as $500^{\circ} \mathrm{C}$ temperature (Miah et al., 2020). The estimated values of the energy storage density, in the upper lines, are based on the assumption that the mixture temperature difference is $\sim 360^{\circ} \mathrm{C}$. However, the mixture can withstand more than this value of temperature difference. Therefore, the mixture could have an energy storage density value as twice as that of water. Beyond the scope of this work and worth mentioning, the fabricated material in this work has been tested under real environmental conditions for one year. The samples have been exposed to a 24 hours thermal cycle, where the sample temperature regularly rises to as high as $\sim 380^{\circ} \mathrm{C}$ and falls to as low as $\sim 5^{\circ} \mathrm{C}$. The material shows outstanding performance in terms of chemical stability, mechanical durability. Moreover, the large variation in temperature during the 24 hours cycle does not affect or deteriorates the material thermal or chemical properties. Nevertheless, a field experimental study is currently being conducted to investigate the performance of the proposed material in this work when integrated into a small scale solar thermal system.

\section{Conclusions}

An experimental study on a new SHS material has been conducted. The material is composed of pure Portland cement and waste cast-iron particle. The produced material, with optimal mixture ratio, shows $\sim 3$ manifold enhancement relative to that of the pure cement, $\sim 6.0 \mathrm{~W} / \mathrm{m} . \mathrm{K}$. The energy storage density of the material show $\sim 17 \%$ enhancement over pure cement, and $\sim$ manifold enhancement over water because the mixture can withstand as high as $500^{\circ} \mathrm{C}$. The following conclusions can be made from the results presented and discussed in the preceding section. This work introduces SHS material with high storage density and high thermal conductivity by using low-cost materials. It is shown experimentally that the produced material is highly appealing for thermal heat storage applications and would be a typical solution for thermal energy storage, especially for small scale solar thermal energy systems. Pure cement mixed with cast iron waste particle with proper weight ratios lead to producing a material with a large volume energy density, higher thermal conductivity with the advantages of being chemically stable, low cost has a long life, non-hazardous, easy to fabricate, and eco-friendly. In this work, only cast-iron particles are studied. However, many forms of metallic waste materials can be implemented as additives to cement to produce a higher quality SHS thermal storage material. The proposed materials, method, and findings in this work open the road for investigating, studying, and utilizing other industrial waste materials for producing high-quality energy storage materials. This work paves the road for implementing the proposed material for SHS in small scale solar thermal systems. Despite that, an investigation of the mixture performance 
conducted under the thermal cycle, not mentioned in this work, further investigations on the performance of the introduced mixture under a long period with thermal cycles are required. All of all, this work succeeds to offer a low-cost SHS heat storage mixture with high energy density, as $\sim 2$ manifold as water, and $\sim 3$ manifold enhancement on thermal conductivity relative to pure cement. Such material is a proper solution for small scale solar thermal applications. By further research, the approach of this work can be applied to produce SHS materials with large energy volume density for large scale solar thermal systems applications.

\section{Nomenclature}

$\begin{array}{lll}A & =\text { Area } & {\left[\mathrm{m}^{2}\right]} \\ C_{p} & =\text { Specific heat capacity } & {[\mathrm{J} / \mathrm{g} \cdot \mathrm{K}]} \\ k & =\text { Thermal conductivity } & {[\mathrm{W} / \mathrm{m} . \mathrm{K}]} \\ \mathrm{L} & =\text { Length } & {[\mathrm{m}]} \\ m & =\text { Mass } & {[\mathrm{g}]} \\ Q & =\text { Energy } & {[\mathrm{J}]} \\ \text { SHS } & =\text { Sensible heat storage } & {[-]} \\ \text { SEM } & =\text { Scanning electronic microscope } & {[-]} \\ T & =\text { Temperature } & {\left[\mathrm{K} .{ }^{\circ} \mathrm{C}\right]} \\ \text { TES } & =\text { Thermal energy storage } & {[-]} \\ \rho & \text { =Density } & {\left[\mathrm{g} / \mathrm{cm}^{3}\right]}\end{array}$

\section{References}

Alva, G., Lingkun L., Xiang H., and F., Guiyin “Thermal energy storage materials and systems for solar energy applications" Renewable and Sustainable Energy Reviews, 68, 693-706 (2017).

Alva, G., Lin Y. and G. Fang "An overview of thermal energy storage systems", Energy, 144, 341-378 (2018).

Armfield company, "HT11C-Linear-Heat-Conduction-Accessory-Instruction-Manual" (no date). Available at:

https://chme.nmsu.edu/files/2014/05/HT11C-Linear-Heat-Conduction-Accessory-Instruction-Manual.pdf (Accessed: 21 July 2020).

Breeze, P., Power Generation Technologies, $3^{\text {rd }}$ End., Chapter 13, Elsevier, Newnes, (2019).

Chen, C., Wang, Q. and D. Yin, "Thermal properties of Mg-11Y-5Gd-2Zn-0.5Zr (wt.\%) alloy”, J. of Alloys and Compounds, 487, 560-563 (2009).

Davis, R. "The effective thermal conductivity of a composite material with spherical inclusions" Int. J., Thermophys, 7, 609-620 (1986).

Helsing, J. and G. Grimvall "Thermal conductivity of cast iron: Models and analysis of experiments", J. of Appl. Physics, 70,1198-1206 (1991).

Ioan, S. and S. Calin “A Comprehensive Review of Thermal Energy Storage”, Sustainability, 10, 191 (2018).

Maxwell, J., A Treatise on Electricity and Magnetism. $2^{\text {nd }}$ Edn., Oxford Univ. Press, Cambridge, pp. 435-441, (1904).

Sarada, K., Yogi, G., Elias, K., Manoj, R., Chand, J., Swetha, P., Jamie, T., Prashanth, S., Muhammad, R., and K., Burton "Thermal energy storage technologies and systems for concentrating solar power plants", Prog. in Energ. and Combus. Sci., 39, 285-319 (2013).

Laing, D., Lehmann, D. and C. Bahl "Concrete storage for solar thermal power plants and industrial process heat", in Eurosolar (Ed.) Conference Proceedings. Third International Renewable Energy Storage Conference (IRES 2008), Berlin. (2008).

Laing, D., and s. Zunft "Using concrete and other solid storage media in thermal energy storage (TES) systems", In Adv. in Therm. Energy Storage Systems: Methods and Applications; Woodhead Publishing: Cambridge, UK, 65-86 (2015)Matthias, G. , Michael, J., and S. Csambor"Advanced CSP Teaching Materials", In: Deutsches Zentrums für Luft- und Raumfahrt e.V.; Institut für Elektrische nsEnergietechnik, Chapter 5- Universität Kassel, (2011).

Matthias, G., Michael J., and S. Csambor "Advanced CSP Teaching Materials. In: Deutsches Zentrums für Luft- und Raumfahrt e.V".; Institut für Elektrische Energietechnik, Chapter 5- Universität Kassel, (2011)

Majdi, H., Sami, K., Meriem, L., Abdelhamid, F., and B. Ali "Energetic and exergetic performances of an economical and available integrated solar storage collector based on concrete matrix", Energy Conv. and Manag., 51,1210-1218 (2010).

Miah, J., Kawsar, A., Suvash, C., Adewumi, J., Sih, Ying., and ̌̌. Branko "Effect of Recycled Iron Powder as Fine Aggregate on the Mechanical, Durability, and High Temperature Behavior of Mortars", Materials, 13, 1168 (2020).

MIPAR Software, "Particle Analysis | Particle Size | Powder Analysis " . Available at: https://www.mipar.us/applications-particles.html (Accessed: 23 July 2020).

Ndiaye, K., Stéphane, G. , and C., Martin “Thermal energy storage based on cementitious materials A review”Aims Energy, 6, 97-120 (2018).

Nomura, T., Okinaka, N., and T. Akiyama "Technology of Latent Heat Storage for High Temperature Application: A Review", ISIJ International, 50, 1229-1239 (2010).

Pietrak, K. and T. Wiśniewski “A review of models for effective thermal conductivity of composite materials”, J. of Power of Tech., 95, 14-24 (2015).

Zare, S. and A. Kargari "Membrane properties in membrane distillation", in Emerging Technologies for Sustainable Desalination Handbook. Elsevier, 107-156. (2018).

Zhao, D., Xin Q., Xiaokun G., Saad A., and Y., Ronggui "Measurement Techniques for Thermal Conductivity and Interfacial Thermal Conductance of Bulk and Thin Film Materials', J. of Elec. Packaging, 138, 040802-040821 (2016). 